\title{
Recognition times of different views of 56 depth-rotated objects: A note concerning Verfaillie and Boutsen (1995)
}

\author{
LUC BOUTSEN and KOEN LAMBERTS \\ University of Birmingham, Birmingham, England \\ and \\ KARL VERFAILLIE \\ Katholieke Universiteit Leuven, Leuven, Belgium
}

\begin{abstract}
The present study examines the effect of the goodness of view on the minimal exposure time required to recognize depth-rotated objects. In a previous study, Verfaillie and Boutsen (1995) derived scales of goodness of view, using a new corpus of images of depth-rotated objects. In the present experiment, a subset of this corpus (five views of 56 objects) is used to determine the recognition exposure time for each view, by increasing exposure time across successive presentations until the object is recognized. The results indicate that, for two thirds of the objects, good views are recognized more frequently and have lower recognition exposure times than bad views.
\end{abstract}

Depending on the relation between the observer and the viewed object, a three-dimensional (3-D) object can project to a multitude of different two-dimensional (2-D) retinal images. In addition, there are an infinite number of possible 3-D worlds that project onto the same 2-D image. Nevertheless, the visual system, under some circumstances, exhibits object constancy or viewpoint invariance (Humphreys \& Quinlan, 1987; Verfaillie, 1992).

One transformation that can thoroughly change the projected shape of an object is a depth rotation. Effects of depth rotations on object recognition have been studied with the use of a variety of stimuli, tasks, subjects, and methods (see, e.g., Biederman \& Gerhardstein, 1993; Bülthoff \& Edelman, 1992; Bülthoff, Edelman, \& Tarr, 1995; Edelman \& Bülthoff, 1992; Humphreys \& Riddoch, 1984, 1985; Lawson \& Humphreys, 1996; Logothetis \& Sheinberg, 1996; Perrett, Oram, Hietanen, \& Benson, 1994; Poggio \& Edelman, 1990; Srinivas, 1993, 1995; Tarr, 1995; Tarr \& Pinker, 1989; Verfaillie, 1993). One way in which the effect of depth rotations on object recognition can be addressed is to examine which views of an object subjects find more easy to identify, and to investigate what determines a good view. In a study involving different behavioral measurements, Palmer, Rosch, and Chase (1981)

This research was conducted by L.B. in partial fulfillment of the requirements for the M.Sc. in Cognitive Science at the University of Birmingham and was supervised by K.L. K.V. is a Research Associate of the Belgian Fund for Scientific Research. We are grateful to Richard Freeman for assistance, to Gert Storms for statistical advice, and to two anonymous reviewers for comments on earlier versions of the manuscript. Correspondence regarding this note should be addressed to L. Boutsen, who is now at the Laboratory of Experimental Psychology, Université Pierre Mendès France, BP 47, 1251 Avenue Centrale, 38040 Grenoble, France (e-mail: luc.boutsen(a)upmf-grenoble.fr). found that the goodness of a view is determined by the objective amount of visual information available in the view (i.e., the amount and visibility of different surfaces of the object) and by the subjective salience of this information to the viewer.

Recently, Verfaillie and Boutsen (1995) constructed a new corpus of images of 70 nameable depth-rotated objects, each depicted in up to 11 perspective views. In a paired-comparison experiment, subjects judged which view in a pair of views was more easy to identify. The name of the object was presented before each pair, and the subjects could study the images as long as they wanted. For each object, a scale of the goodness of the views was derived by Thurstonian scaling of the subjects' preferences. An exploratory cluster analysis was performed on the scaling solutions of the 57 objects depicted in 11 views. (The remaining 13 objects were depicted in fewer than 11 different views; because these objects contain several planes of symmetry, they projected to the same image when seen from different vantage points.) The 57 objects were grouped into eight clusters. Cluster membership was characterized by the coarse physical structure of the member objects. The orientation of this structure in a viewing sphere (Figure 1) determined the goodness of the views.

Whereas Verfaillie and Boutsen (1995) examined the judged typicality of views, we used a subset of the corpus in order to study the effect of the vantage point from which an object is viewed on the recognition exposure timethat is, the minimal presentation time required for recognition of the object. The recognition exposure time of an object in a given view was determined by increasing the exposure time of the image across repeated presentations until the object is recognized. 


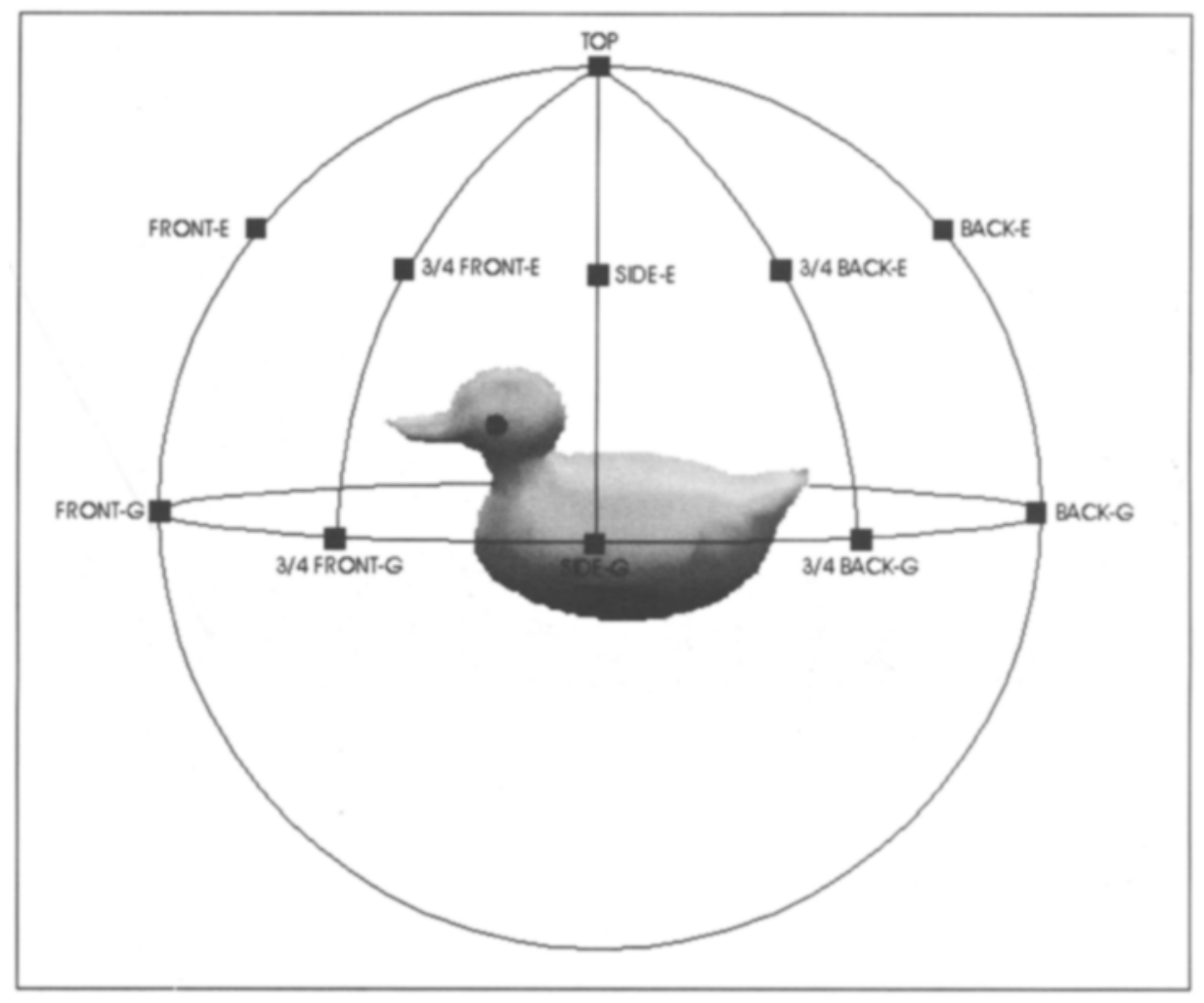

Figure 1. A duck placed in the viewing sphere and the 11 perspective views. From "A Corpus of 714 Full-Color Images of Depth-Rotated Objects," by K. Verfaillie and L. Boutsen, 1995, Perception \& Psychophysics, 57, p. 927 . Copyright 1995 by the Psychonomic Society, Inc.

We also examined whether goodness of view was consistent across tasks. In this case, recognition exposure times for views that were rated as good views in Verfaillie and Boutsen's (1995) study should be shorter than those for views that were rated as bad.

\section{METHOD}

\section{Subjects}

Twenty-five graduate students ( 14 men and 11 women) from the University of Birmingham participated in the experiment. All subjects had normal or corrected-to-normal vision. They were paid $£ 4$.

\section{Stimuli and Apparatus}

Images of 56 real-world, mainly man-made objects, each depicted in five perspective views, were used in the experiment. The $280 \mathrm{im}$ ages formed a subset of the corpus of images developed by Verfaillie and Boutsen (1995). This subset contained all of the objects that were included in the cluster analysis by Verfaillie and Boutsen, except for one, a Belgian call box, which was excluded from presentation because the British subjects were not familiar with its design. All objects were presented in gray level colors on a uniformly white background without texture, which, therefore, contained no depth cues. Also, there were no cast shadows in the images.

For the construction of the views, each object was placed in an imaginary viewing sphere in such a way that its main plane of symmetry coincided with the midsagittal plane in the viewing sphere- that is, the plane containing the $z$-axis, or the horizontal axis through the sphere's center in Figure 1 , and the $y$-axis (the vertical axis through the sphere's center). Moreover, for mono-oriented objects (which normally appear in an upright orientation in an environmentcentered reference frame), their top-bottom axis, front-back axis, and left-right axis corresponded with the sphere's $y$-axis, $z$-axis, and $x$-axis, respectively. For poly-oriented objects (which lack a prototypical upright orientation), their axis of elongation was aligned with the sphere's $z$-axis. (For details about the construction of the images, see Verfaillie and Boutsen, 1995.)

The objects had exactly the same projected size along their longest axis. To their largest horizontal extent, the objects occupied almost half of the screen width (49\%). In the present experiment, all objects fell within an area of approximately $5.3^{\circ} \times 5.5^{\circ}$, centered on the screen.

The five orientations were all ground level $(G)$ views - that is, views taken from the equator of the right side of the viewing sphere (Figure 1). The angular difference between the views was $45^{\circ}$. In the Front-G and Back-G views, the observer's line of sight coincided with the two ends of the $z$-axis. In the $3 / 4$ Front-G and $3 / 4$ Back-G views, the object was in an orientation between the Front-G and Side$G$ views and between the Back-G and Side- $G$ views, respectively.

A pattern mask was prepared by combining parts of three images from the set. The mask covered the whole screen.

The experiment was controlled by a Pentium computer. The images were presented on a 15 -in. Super VGA color monitor with a vertical refresh rate of $60 \mathrm{~Hz}$. The images, including the mask, were displayed with a resolution of $640 \times 480$ pixels. 


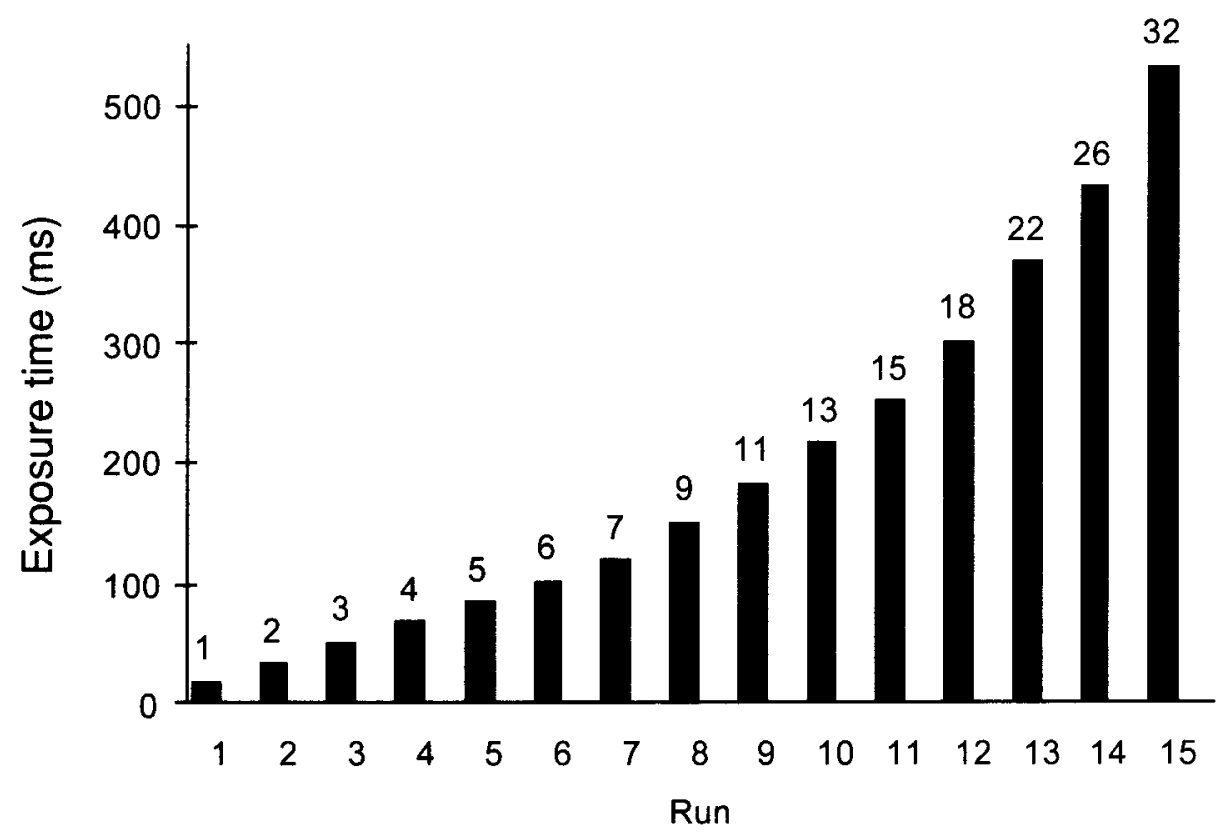

Figure 2. The exposure times, expressed in number of frames of vertical refresh (printed above each bar). One frame is $16.6 \mathrm{msec}$.

\section{Design}

The 280 images were arranged into five sets of 56 images each, in which all objects were present in one of five orientations. Each subject viewed one set of images and thus was presented with each object in only one view. Each set was administered to 5 subjects.

\section{Procedure}

One session consisted of several runs through one set of $56 \mathrm{im}$ ages. At each next run, the exposure time was increased, and those images that were not recognized in the previous run were presented again. The minimal exposure time, being one frame or vertical refresh, was $16.6 \mathrm{msec}$. Between consecutive runs, the exposure time was increased exponentially, as is indicated in Figure 2. The experiment was terminated when a subject failed to identify any of the remaining images in two consecutive runs. The presentation order of the images was randomized before each run.

During each trial, the following sequence was presented. First, a white screen with a black fixation cross at the center appeared for $500 \mathrm{msec}$. This was followed by the image. After the image, the mask appeared for $250 \mathrm{msec}$, followed by a uniformly white screen. This screen disappeared after the subject named the object. The experimenter then verified the subject's answer, and, to increase motivation, feedback was provided by means of a high-pitched tone for a correct answer and a low-pitched tone for an incorrect answer. The subjects were not allowed to give more than one answer at each trial. When an image was identified, it was never presented again to the subject in the next runs.

Each subject was tested individually. The subjects sat approximately $150 \mathrm{~cm}$ from the screen in a dark room. Detailed written instructions encouraged the subjects to give the name of a single item, not a description, when naming the objects. The subjects were not told the names of the objects in advance. No emphasis was laid on the fact that the objects were presented in different depth orientations. One session took about $75 \mathrm{~min}$.

\section{RESULTS AND DISCUSSION}

During each session, the subjects identified, on average, 36.3 of the 56 objects $(S D=2.58)$. Most of the identified objects were recognized at exposure times of between 16.6 and $68 \mathrm{msec}(86.9 \%)$ - that is, after four presentations - and especially at 33 or $50 \mathrm{msec}(69.3 \%)$ - that is, after two or three presentations, respectively (Figure 3 ). The mean exposure time at which objects were recognized was $51 \mathrm{msec}(S D=39 \mathrm{msec})$. Three objects (the scissors, racket, and spanner) were never recognized in any view. Incorrect responses were don't know responses or names of objects that were not included in the set.

The experiment was terminated when a subject failed to identify any of the objects in two consecutive runs. On average, this occurred after 10 or 11 presentations - that is, at a mean exposure time of $220 \mathrm{msec}(S D=111.3 \mathrm{msec})$. Only one subject viewed the images until the maximum presentation time of $536 \mathrm{msec}$ ( 15 runs).

Note that the large discrepancy between the mean exposure time at which objects were recognized $(51 \mathrm{msec})$ and the exposure time at which the experiment was terminated $(220 \mathrm{msec})$ and the fact that very few objects were recognized at the longer exposure times (Figure 3 ) suggest that the unrecognized views probably still would not be identified when presented at longer exposure times.

In Appendix A, the mean recognition exposure times of each object in each view are presented. The mean recognition exposure time is based on a minimum of one and a maximum of five observations, as each image was pre- 


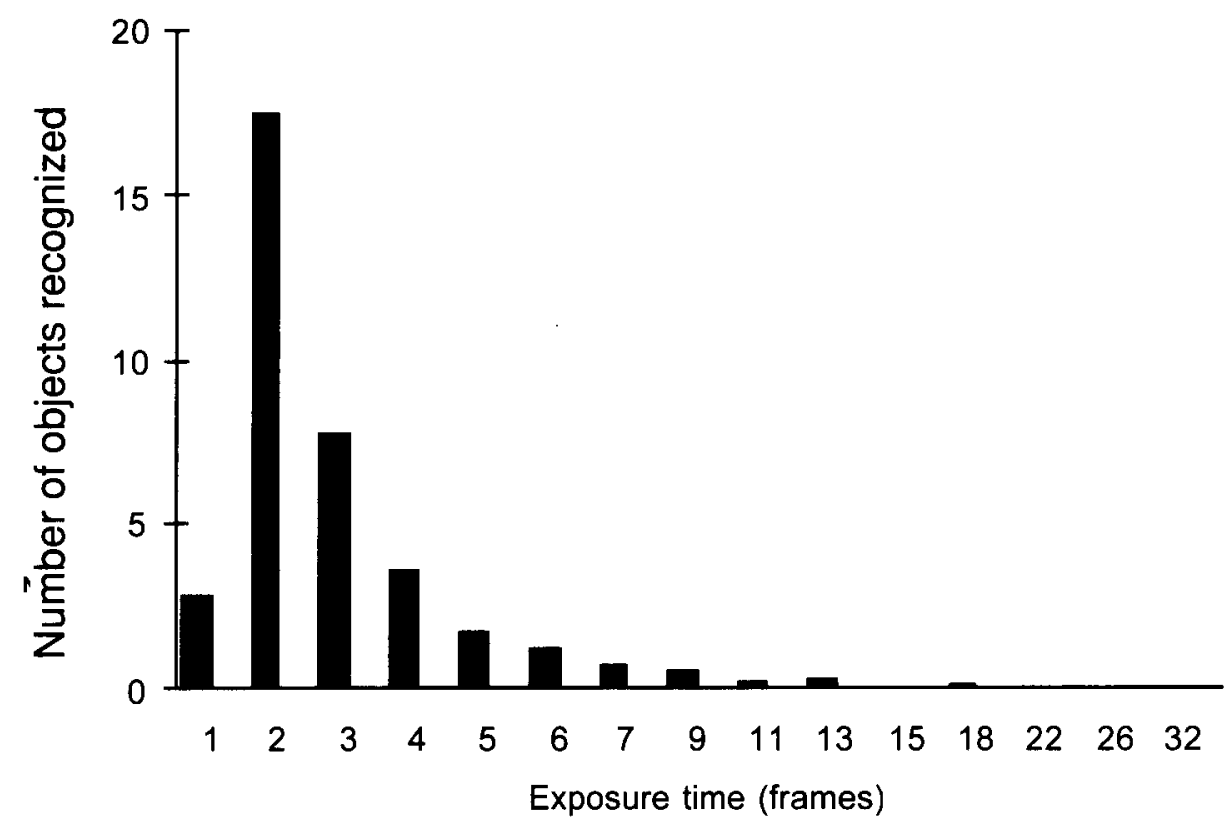

Figure 3. The mean number of objects recognized, as a function of exposure time.

sented to 5 subjects. One fifth of the images $(58 / 280)$ were never recognized, and more than half of the images (144/ 280 ) were recognized by all 5 subjects. Moreover, $17 \mathrm{ob}-$ jects were identified in all views by nearly all ( 24 or 25$)$ subjects (Appendix B).

Correlation analyses were performed in order to compare, for a number of objects, the recognition exposure times with the corresponding scale values obtained in the rating study by Verfaillie and Boutsen (1995). Pearson's product-moment correlations $(r)$ were computed between the logarithmically transformed recognition exposure times of the views and their corresponding scale values. Twelve of the 56 objects that were recognized by 10 or fewer subjects were not included in the correlation analyses. A two-tailed $t$ test was performed for each correlation.

In the first correlation analysis, only the trials in which the view was recognized were included in the computation of the correlations. All correlations in this analysis are based on a minimum of 11 and a maximum of 25 observations. The results are presented in the third and fourth columns of the table in Appendix B. The objects are ordered according to their degree of cluster membership, as determined by Verfaillie and Boutsen (1995). Because the better views have smaller scale values, positive correlations indicate that those objects in views that were evaluated as being better required a smaller exposure time to be recognized. Only for 18 of the 44 objects were the positive correlations statistically significant at least at the $5 \%$ level.

However, this analysis only included the recognition exposure times of the views that were actually recognized; the fact that some views were recognized more frequently than other views was ignored. Therefore, the second analysis took into account accuracy of identification. The trials in which the view was not recognized were included in the correlation by setting an arbitrary, high recognition exposure time-namely, the first multiple of $30 \mathrm{msec}$ above the highest individual recognition exposure time for that object. Thus, all correlations in this analysis are based on 25 observations (i.e., real and arbitrary recognition exposure times of 5 subjects observing five views). The results are presented in the fifth and sixth columns of the table in Appendix B. For all the objects but 2 (the tricycle and the perforator), which were recognized by fewer than 25 subjects, the correlations increased when the views that were not recognized were included in the analysis. For 30 of the 44 objects, the positive correlations were now statistically significant at least at the $5 \%$ level.

There seems to be a relationship between the number of significant correlations and cluster membership, especially in the second analysis. Most objects in the first, third, fifth, and eighth clusters had significant correlations, whereas few or none had significant correlations in the second and sixth clusters. Most objects in the fourth and seventh clusters were not recognized at all.

Results per cluster. For 8 of the 10 objects in the first cluster, the analysis that included the views that were not recognized yielded a significant positive correlation. The main reason is the fact that the objects in this cluster are elongated along their front-back axis, so that the Front-G and Back-G views reveal the smallest surfaces. Therefore, these views were rated as the worst views in the rating study and were recognized by fewer subjects and/or at higher exposure times in the present study. 
The objects in the second cluster also have an evident top-bottom and front-back axis. However, in contrast to the first cluster, most objects are more extended in the direction of the top-bottom axis than in the direction of the front-back axis. Therefore, none of the $\mathrm{G}$ views are foreshortened. These views were generally rated as being better than those in the first cluster, and, for some objects, the recognition exposure times of most views did not differ markedly. This explains why the correlation between ratings and exposure times was significant for only one of the nine objects.

The third cluster contains the largest proportion of objects that were recognized in all views by all the subjects (7/11). For 7 of the 11 objects, the correlation between ratings and recognition exposure times was significant, essentially for the same reason as in the first cluster. Because the objects are more or less elongated along their frontback axis, the views revealing the side of the objects are most diagnostic: The $3 / 4$ Front-G, 3/4 Back-G, and Side-G views were all rated as better views and recognized more rapidly than were the Front-G and Back-G views.

The six most prototypical members of the fourth cluster were recognized by fewer than 8 subjects. Moreover, this cluster contains the only three objects (the scissors, spanner, and racket) that were never recognized in any view. The basis for this finding is that the objects are more or less flat in the midtransverse plane, which makes the top plane critical for identification. Viewed from a nonelevated angle, however, the top plane is not visible. It is not surprising, then, that, in the present study, in which observers only viewed $G$ views, most views could not be identified. Note that, in the rating study, all $G$ views were rated as the worst views, which converges with the present findings.

The objects in the fifth cluster are also flat, but, in contrast to the previous cluster, they are flat in the midsagittal plane rather than in the midtransverse plane. This makes their side critical for identification. In the rating study, the foreshortened Front-G and Back-G views were, indeed, rated as the worst views. These views were also recognized less frequently and more slowly, which explains why the correlations (including the unrecognized views) were significant for all the objects.

Three of the five objects in the sixth cluster were not recognized by more than 10 subjects, either because the instances of the objects were probably unfamiliar to British subjects (as, e.g., in the case of the telephone) or because the $G$ views led to accidents of viewpoint, in which regular 2-D shapes emerged that were undiagnostic of the 3-D object (as, e.g., in the case of the book).

Because of foreshortening (the foreshortened views were also rated as the worst views), the two objects in the seventh cluster were not recognized by more than 10 subjects.

Finally, for the two objects in the eighth cluster, significant correlations were obtained. This has to do with the fact that the objects' fronts are more diagnostic than their backs, so that the Front-G and $3 / 4$ Front-G views were both rated as the best views and recognized most easily.

\section{GENERAL DISCUSSION}

The primary goal of this study was to examine the speed of recognition for five views of 56 depth-rotated objects and, hence, to provide additional information about the stimulus set described by Verfaillie and Boutsen (1995). We hope that the present data about this subset of the corpus of images, in combination with those from the rating study, may be useful in constructing stimulus sets for use in research about the recognition of depth-rotated objects.

The present study suggests that the amount of visual information present in a view (Palmer et al., 1981; Verfaillie \& Boutsen, 1995) was a major determinant of the recognition time of the view. Views that revealed the smallest amount of the surfaces of objects were identified at higher exposure times (the Front- $G$ and the Back- $G$ views, for most objects in the present set), were recognized by fewer subjects, or were not identified at all. For more than half of the objects, the $3 / 4$ Front-G and $3 / 4$ Back-G views, which simultaneously revealed aspects of the objects' fronts, backs, and sides, were most easy to identify.

Second, a number of objects in this set (most objects of the fourth, sixth, and seventh clusters) were difficult to recognize in all views. This probably was due to the sample of viewpoints used in the present study. All the objects were viewed from a nonelevated angle that led to foreshortening of flat and/or elongated objects.

Third, for two-thirds of the objects, there was a relation between the goodness-of-view ratings and the minimal exposure times needed for recognition. The views that were rated as better views were also recognized more frequently and more rapidly. Moreover, for the objects that were almost never recognized in the present study (especially in the fourth cluster), the five selected views were also rated as the worst views in Verfaillie and Boutsen (1995).

We are aware of the fact that the notion of objective amount of information available in the image (as opposed to more subjective factors, such as familiarity) is vague, even when framed as the number of surfaces available. We are presently exploring the possibility of quantifying the information objectively present in a given view (see, e.g., Freeman, 1994, 1996; Weinshall, Werman, \& Tishby, 1996), in order to relate judged goodness and recognition times to objective image properties (the work of Cutzu \& Edelman, 1994, shows that this does not necessarily preclude the potential of accounting for subject-specific, idiosyncratic factors), but this is beyond the scope of the present note.

\section{REFERENCES}

Biederman, I., \& Gerhardstein, P. C. (1993). Recognizing depthrotated objects: Evidence and conditions for three-dimensional viewpoint invariance. Journal of Experimental Psychology: Human Perception \& Performance, 19, 1162-1182.

Bülthoff, H. H., \& Edelman, S. (1992). Psychophysical support for a two-dimensional view interpolation theory of object recognition. Proceedings of the National Academy of Sciences, 89, 6064. 
Bülthoff, H. H., Edelman, S. Y., \& Tarr, M. J. (1995). How are threedimensional objects represented in the brain? Cerebral Cortex, $\mathbf{5}$, 247-260.

Cutzu, F., \& Edelman, S. (1994). Canonical views in object representation and recognition. Vision Research, 34, 3037-3056.

EdelmaN, S., \& BülthoFf, H. H. (1992). Orientation dependence in the recognition of familiar and novel views of $3 \mathrm{D}$ objects. Vision Research, 32, 2385-2400

FREEMAN, W. T. (1994). The generic view assumption in a framework for visual perception. Nature, 368, 542-545.

FreEMAN, W. T. (1996). Exploiting the generic viewpoint assumption. International Journal of Computer Vision, 20, 243-261.

HUMPhreys, G. W., \& Quinlan, P. T. (1987). Normal and pathological processes in visual object constancy. In G. W. Humphreys \& M. J. Riddoch (Eds.), Visual object processing: A cognitive neuropsychological approach (pp. 43-105). Hillsdale, NJ: Erlbaum.

HumphreYs, G. W., \& RidDoch, M. J. (1984). Routes to object constancy: Implications from neurological impairments of object constancy. Quarterly Journal of Experimental Psychology, 36A, 385-415.

HumPhrEYs, G. W., \& RiDDOCH, M. J. (1985). Authors' correction to "Routes to object constancy." Quarterly Journal of Experimental Psychology, 37A, 493-495.

LaWSON, R., \& HuMPhrEYs, G. W. (1996). View specificity in object processing: Evidence from picture matching. Journal of Experimental Psychology: Human Perception \& Performance, 22, 395-416.

Logothetis, N. K., \& Sheinberg, D. L. (1996). Visual object recognition. Annual Review of Neuroscience, 19, 577-621.

Palmer, S., Rosch, E., \& Chase, P. (1981). Canonical perspective and the perception of objects. In J. Long \& A. Baddeley (Eds.), Attention and performance $I X$ (pp. 135-151). Hillsdale, NJ: Erlbaum.

Perrett, D. I., Oram, M. W., Hietanen, J. K., \& Benson, P. J. (1994). Issues of representation in object vision. In M. J. Farah \& G. Ratcliff (Eds.), The neuropsychology of high-level vision (pp. 33-61). Hillsdale, NJ: Erlbaum.

Poggio, T., \& Edelman, S. (1990). A network that learns to recognize three-dimensional objects. Nature, 343, 263-266.

SRINIVAS, K. (1993). Perceptual specificity in nonverbal priming. Journal of Experimental Psychology: Learning, Memory, \& Cognition, 19, 582-602.

SRINIVAS, K. (1995). Representation of rotated objects in explicit and implicit memory. Journal of Experimental Psychology: Learning, Memory, \& Cognition, 21, 1019-1036.

TARR, M. J. (1995). Rotating objects to recognize them: A case study on the role of viewpoint dependency in the recognition of threedimensional objects. Psychonomic Bulletin \& Review, 2, 55-82.

TARR, M. J., \& PINkER, S. (1989). Mental rotation and orientationdependence in shape recognition. Cognitive Psychology, 21, 233-282. VERFAILLIE, K. (1992). Variant points of view on viewpoint invariance. Canadian Journal of Psychology, 46, 215-235.

VERFAILLIE, K. (1993). Orientation-dependent priming effects in the perception of biological motion. Journal of Experimental Psychology: Human Perception \& Performance, 19, 992-1013.

Verfaillie, K., \& BoutSen, L. (1995). A corpus of 714 full-color images of depth-rotated objects. Perception \& Psychophysics, 57, 925-961.

Weinshall, D., Werman, M. \& Tishby, N. (1996). Stability and likelihood of views of three-dimensional objects. Computing Supplementum, 11, 237-256.

APPENDIX A

The Number of Subjects Who Recognized the Objects, the Mean Recognition Exposure Times (ET, in Milliseconds) of Each View, and the Number of Subjects Who Recognized Each View per Object ( $n$ )

\begin{tabular}{|c|c|c|c|c|c|c|c|c|c|c|c|}
\hline \multirow{2}{*}{ Object } & \multirow[b]{2}{*}{ No. Subjects } & \multicolumn{2}{|c|}{ Front-G } & \multicolumn{2}{|c|}{$3 / 4$ Front-G } & \multicolumn{2}{|c|}{ Side-G } & \multicolumn{2}{|c|}{$3 / 4$ Back-G } & \multicolumn{2}{|c|}{ Back-G } \\
\hline & & $\overline{\mathrm{ET}}$ & $n$ & ET & $\bar{n}$ & ET & $\bar{n}$ & ET & $\bar{n}$ & ET & $n$ \\
\hline \multicolumn{12}{|l|}{ Cluster 1 } \\
\hline roller skate & 13 & 67 & 1 & 96 & 4 & 92 & 2 & 84 & 4 & 184 & 2 \\
\hline piano & 25 & 47 & 5 & 30 & 5 & 33 & 5 & 30 & 5 & 47 & 5 \\
\hline stapler & 14 & - & 0 & 36 & 5 & 44 & 5 & 34 & 4 & - & 0 \\
\hline skateboard & 15 & - & 0 & 67 & 5 & 34 & 5 & 67 & 5 & - & 0 \\
\hline tricycle & 23 & 40 & 5 & 38 & 4 & 33 & 4 & 51 & 5 & 42 & 5 \\
\hline razor blade & 2 & - & 0 & - & 0 & 50 & 1 & 217 & 1 & - & 0 \\
\hline fighter jet & 25 & 47 & 5 & 34 & 5 & 33 & 5 & 33 & 5 & 78 & 5 \\
\hline shoe & 24 & 60 & 5 & 30 & 5 & 27 & 5 & 27 & 5 & 88 & 4 \\
\hline pitchfork & 14 & - & 0 & 50 & 5 & 240 & 3 & 60 & 5 & 302 & 1 \\
\hline pan & 16 & - & 0 & 50 & 5 & 50 & 5 & 44 & 5 & 84 & 1 \\
\hline \multicolumn{12}{|l|}{ Cluster 2} \\
\hline ventilator & 25 & 34 & 5 & 43 & 5 & 40 & 5 & 34 & 5 & 54 & 5 \\
\hline extinguisher & 21 & 67 & 4 & 60 & 5 & 67 & 2 & 40 & 5 & 50 & 5 \\
\hline globe & 24 & 37 & 5 & 33 & 5 & 27 & 5 & 30 & 5 & 42 & 4 \\
\hline concrete mixer & 16 & 89 & 3 & 60 & 5 & 67 & 1 & 50 & 3 & 59 & 4 \\
\hline desk lamp & 24 & 41 & 5 & 37 & 5 & 34 & 5 & 30 & 5 & 88 & 4 \\
\hline perforator & 13 & 67 & 4 & 63 & 4 & 59 & 2 & - & 0 & 61 & 3 \\
\hline watch & 18 & 37 & 5 & 40 & 5 & - & 0 & 50 & 3 & 40 & 5 \\
\hline oil lamp & 25 & 64 & 5 & 50 & 5 & 50 & 5 & 47 & 5 & 57 & 5 \\
\hline \multicolumn{12}{|l|}{ Cluster 3} \\
\hline cow & 25 & 40 & 5 & 34 & 5 & 27 & 5 & 34 & 5 & 37 & 5 \\
\hline helicopter & 25 & 53 & 5 & 34 & 5 & 34 & 5 & 30 & 5 & 90 & 5 \\
\hline car & 25 & 33 & 5 & 27 & 5 & 33 & 5 & 27 & 5 & 41 & 5 \\
\hline truck & 25 & 67 & 5 & 37 & 5 & 37 & 5 & 37 & 5 & 54 & 5 \\
\hline train & 25 & 60 & 5 & 40 & 5 & 40 & 5 & 37 & 5 & 74 & 5 \\
\hline roller & 13 & 42 & 2 & 76 & 4 & 151 & 1 & 74 & 5 & 218 & 1 \\
\hline chicken & 25 & 44 & 5 & 34 & 5 & 30 & 5 & 30 & 5 & 47 & 5 \\
\hline duck & 21 & 64 & 5 & 34 & 5 & 34 & 5 & 37 & 5 & 84 & 1 \\
\hline teapot & 19 & 95 & 3 & 34 & 5 & 30 & 5 & 33 & 5 & 117 & 1 \\
\hline fork-lift truck & 18 & 72 & 3 & 39 & 3 & 60 & 5 & 77 & 5 & 76 & 2 \\
\hline bench & 25 & 37 & 5 & 41 & 5 & 90 & 5 & 40 & 5 & 40 & 5 \\
\hline
\end{tabular}


Appendix A (Continued)

\begin{tabular}{|c|c|c|c|c|c|c|c|c|c|c|c|}
\hline \multirow[b]{2}{*}{ Object } & \multirow[b]{2}{*}{ No. Subjects } & \multicolumn{2}{|c|}{ Front-G } & \multicolumn{2}{|c|}{ 3/4 Front-G } & \multicolumn{2}{|c|}{ Side-G } & \multicolumn{2}{|c|}{ 3/4 Back-G } & \multicolumn{2}{|c|}{ Back-G } \\
\hline & & $\overline{\mathrm{ET}}$ & $n$ & ET & $n$ & $\overline{E T}$ & $n$ & ET & $\bar{n}$ & $\overline{\mathrm{ET}}$ & $n$ \\
\hline \multicolumn{12}{|l|}{ Cluster 4} \\
\hline scissors & 0 & - & 0 & - & 0 & - & 0 & - & 0 & - & 0 \\
\hline spanner & 0 & - & 0 & - & 0 & - & 0 & - & 0 & - & 0 \\
\hline spade & 7 & - & 0 & - & 0 & 77 & 5 & 92 & 2 & - & 0 \\
\hline tin opener & 1 & - & 0 & 151 & 1 & - & 0 & - & 0 & - & 0 \\
\hline racket & 0 & - & 0 & - & 0 & - & 0 & - & 0 & - & 0 \\
\hline rubber dinghy & 6 & 185 & 1 & 84 & 1 & 101 & 1 & 185 & 2 & 50 & 1 \\
\hline hair brush & 21 & 95 & 3 & 47 & 5 & 60 & 5 & 37 & 5 & 78 & 3 \\
\hline fork & 17 & 134 & 2 & 43 & 5 & 76 & 2 & 54 & 5 & 84 & 3 \\
\hline screwdriver & 14 & - & 0 & 34 & 4 & 40 & 5 & 47 & 5 & - & 0 \\
\hline \multicolumn{12}{|l|}{ Cluster 5} \\
\hline axe & 15 & - & 0 & 57 & 5 & 30 & 5 & 50 & 5 & - & 0 \\
\hline bicycle & 25 & 51 & 5 & 26 & 5 & 23 & 5 & 23 & 5 & 70 & 5 \\
\hline saw & 15 & - & 0 & 37 & 5 & 33 & 5 & 43 & 5 & - & 0 \\
\hline toothbrush & 15 & - & 0 & 40 & 5 & 33 & 5 & 33 & 5 & - & 0 \\
\hline harp & 15 & - & 0 & 24 & 5 & 20 & 5 & 24 & 5 & - & 0 \\
\hline knife & 13 & - & 0 & 55 & 4 & 64 & 5 & 93 & 4 & - & 0 \\
\hline motorbike & 25 & 57 & 5 & 30 & 5 & 30 & 5 & 23 & 5 & 87 & 5 \\
\hline biro & 18 & 50 & 1 & 37 & 5 & 33 & 5 & 40 & 5 & 152 & 2 \\
\hline fish & 21 & 63 & 4 & 30 & 5 & 33 & 5 & 33 & 5 & 84 & 2 \\
\hline \multicolumn{12}{|l|}{ Cluster 6} \\
\hline telephone & 2 & - & 0 & 369 & 1 & - & 0 & 184 & 1 & - & 0 \\
\hline armchair & 25 & 44 & 5 & 30 & 5 & 33 & 5 & 33 & 5 & 37 & 5 \\
\hline glasses & 17 & 34 & 4 & 40 & 5 & - & 0 & 54 & 5 & 39 & 3 \\
\hline book & 10 & 42 & 2 & 134 & 2 & 33 & 1 & 51 & 4 & 100 & 1 \\
\hline binder & 3 & 302 & 1 & 100 & 1 & - & 0 & - & 0 & 84 & 1 \\
\hline \multicolumn{12}{|l|}{ Cluster 7} \\
\hline file & 6 & - & 0 & 100 & 1 & 63 & 4 & 117 & 1 & - & 0 \\
\hline corkscrew & 1 & - & 0 & 101 & 1 & - & 0 & - & 0 & - & 0 \\
\hline \multicolumn{12}{|l|}{ Cluster 8} \\
\hline petrol pump & 20 & 54 & 5 & 37 & 5 & 42 & 4 & 72 & 3 & 56 & 3 \\
\hline shaver & 14 & 79 & 4 & 50 & 5 & 123 & 3 & 84 & 2 & & 0 \\
\hline
\end{tabular}

APPENDIX B

The Number of Subjects Who Recognized the Views, Pearson's Product-Moment Correlations, and Student $t$ Values per Object

\begin{tabular}{lccccc}
\hline & \multicolumn{3}{c}{$\begin{array}{c}\text { Pearson's } r, \\
\text { Excluding Views }\end{array}$} & \multicolumn{3}{c}{$\begin{array}{c}\text { Pearson's } r, \\
\text { Including Views } \\
\text { Object }\end{array}$} & No. Subjects & Not Recognized & $t^{\text {a }}$ & Nocognized & $t^{b}$ \\
\hline $\begin{array}{l}\text { Cluster 1 } \\
\text { roller skate }\end{array}$ & 13 & .212 & 0.719 & $.423^{*}$ & 2.244 \\
piano & 25 & $.447^{*}$ & 2.396 & $.447^{*}$ & 2.399 \\
stapler & 14 & .176 & 0.619 & $.833 \ddagger$ & 7.229 \\
skateboard & 15 & -.445 & 1.791 & $.702 \ddagger$ & 4.735 \\
tricycle & 23 & .036 & 0.165 & -.117 & 0.866 \\
razor blade & 2 & & & & \\
fighter jet & 25 & $.554 \dagger$ & 3.191 & $.554 \dagger$ & 3.191 \\
shoe & 24 & $.697 \ddagger$ & 4.559 & $.748 \ddagger$ & 5.405 \\
pitchfork & 14 & $.802 \ddagger$ & 4.651 & $.917 \ddagger$ & 11.063 \\
pan & 16 & .209 & 0.799 & $.642 \ddagger$ & 4.020 \\
Cluster 2 & & & & & \\
$\quad$ ventilator & 25 & .368 & 1.898 & .368 & 0.898 \\
extinguisher & 21 & .105 & 0.460 & .218 & 1.071 \\
globe & 24 & .117 & 0.552 & .162 & 0.791 \\
concrete mixer & 16 & -.004 & 0.015 & .141 & 0.686 \\
desk lamp & 24 & $.598 \dagger$ & 3.499 & $.637 \ddagger$ & 3.971 \\
perforator & 13 & .192 & 0.648 & -.116 & 0.564 \\
watch & 18 & .006 & 0.024 & .361 & 1.858 \\
oil lamp & 25 & .357 & 1.839 & .357 & 1.838
\end{tabular}


Appendix B (Continued)

\begin{tabular}{|c|c|c|c|c|c|}
\hline \multicolumn{6}{|c|}{ Appendix B (Continued) } \\
\hline Object & No. Subjects & $\begin{array}{c}\text { Pearson's } r \\
\text { Excluding Views } \\
\text { Not Recognized }\end{array}$ & $t^{\mathrm{a}}$ & $\begin{array}{c}\text { Pearson's } r \\
\text { Including Views } \\
\text { Not Recognized }\end{array}$ & $\mathbf{t}^{b}$ \\
\hline Cluster 3 & & & & & \\
\hline cow & 25 & .298 & 1.497 & .298 & 1.497 \\
\hline helicopter & 25 & $.706 \ddagger$ & 4.780 & $.706 \ddagger$ & 4.780 \\
\hline car & 25 & $.414^{*}$ & 2.181 & $.414^{*}$ & 2.181 \\
\hline truck & 25 & $.610 \dagger$ & 3.691 & $.610 \dagger$ & 3.691 \\
\hline train & 25 & $.728 \ddagger$ & 5.092 & $.728 \ddagger$ & 5.092 \\
\hline roller & 13 & .206 & 0.698 & $.546 \dagger$ & 3.129 \\
\hline chicken & 25 & .354 & 1.815 & .354 & 1.815 \\
\hline duck & 21 & $.845 \ddagger$ & 6.887 & $.919 \ddagger$ & 11.242 \\
\hline teapot & 19 & $.915 \ddagger$ & 9.350 & $.949 \ddagger$ & 14.497 \\
\hline fork-lift truck & 18 & .296 & 1.239 & .343 & 1.754 \\
\hline bench & 25 & -.057 & 0.273 & -.057 & 0.273 \\
\hline \multicolumn{6}{|l|}{ Cluster 4} \\
\hline scissors & 0 & & & & \\
\hline spanner & 0 & & & & \\
\hline spade & 7 & & & & \\
\hline tin opener & 1 & & & & \\
\hline racket & 0 & & & & \\
\hline rubber dinghy & 6 & & & & \\
\hline hair brush & 21 & $.708 \ddagger$ & 4.369 & $.773 \ddagger$ & 5.856 \\
\hline fork & 17 & $.546^{*}$ & 2.524 & $.685 \ddagger$ & 4.519 \\
\hline screwdriver & 14 & -.149 & 0.522 & $.681 \ddagger$ & 4.468 \\
\hline \multicolumn{6}{|l|}{ Cluster 5} \\
\hline axe & 15 & .185 & 0.678 & $.822 \ddagger$ & 6.940 \\
\hline bicycle & 25 & $.778 \ddagger$ & 5.938 & $.778 \ddagger$ & 5.938 \\
\hline saw & 15 & -.443 & 1.781 & $.793 \ddagger$ & 6.261 \\
\hline toothbrush & 15 & -.328 & 1.251 & $.866_{+}^{\ddagger}$ & 8.305 \\
\hline harp & 15 & -.114 & 0.413 & $.868 \ddagger$ & 8.383 \\
\hline knife & 13 & .020 & 0.066 & $.749 \ddagger$ & 5.429 \\
\hline motorbike & 25 & $.619 \dagger$ & 3.779 & $.619 \dagger$ & 3.780 \\
\hline biro & 18 & $.651 \dagger$ & 3.430 & $.873 \ddagger$ & 8.634 \\
\hline fish & 21 & $.856 \ddagger$ & 7.217 & $.899 \ddagger$ & 9.861 \\
\hline \multicolumn{6}{|l|}{ Cluster 6} \\
\hline telephone & 2 & & & & \\
\hline armchair & 25 & .294 & 1.475 & .294 & 1.475 \\
\hline glasses & 17 & $-.541^{*}$ & 2.491 & -.103 & 0.499 \\
\hline book & 10 & & & & \\
\hline binder & 3 & & & & \\
\hline \multicolumn{6}{|l|}{ Cluster 7} \\
\hline file & 6 & & & & \\
\hline corkscrew & 1 & & & & \\
\hline \multicolumn{6}{|l|}{ Cluster 8} \\
\hline petrol pump & 20 & .286 & 1.266 & $.520^{*}$ & 2.466 \\
\hline shaver & 14 & .467 & 1.829 & $.707 \ddagger$ & 4.468 \\
\hline
\end{tabular}

(Manuscript received September 12, 1996; revision accepted July 24,1997 .) 